\title{
Infectologia velha e infectologia nova: concepção extravagante
}

\author{
Old infectology and new infectology: an extravagant conception
}

\section{Senhor Editor:}

Até 0 início dos anos cinquienta do século passado a Infectologia, no Brasil, não fazia parte do elenco de atividades médicas. Pouquíssimos profissionais tinham alguma vinculação com assistência específica relacionada com doenças infecciosase parasitárias. Lembrome de determinados pioneiros, que se dedicavam à Cínica Médica mas mostravam interesse pelas enfermidades citadas, sem especialização particularizada. A propósito, julgo correto mencionar Arary da Cruz Tiriba com Jair Xavier Guimarães, em São Paulo, e José Rodrigues da Silva no Rio de Janeiro. Também, nesse contexto, rememoro que um dos meus mais destacados mestres dizia-me claramente que concordava com a ação de clínicos com preparo algo especial quanto aos males causados por microrganismos ou parasitas.

A partir daquele momento ficou patente que se tornava conveniente conceder nova feição à área antes quase nada individualizada. Pessoalmente passei a defender mudança da situação e comecei a atuar só como infectologista.

Infectologia é o ramo da Medicina que constitui concreta especialidade, englobando em seus desiderados tarefas exclusivas pertinentes a atendimento aos acometidos de doença infectoparasitárias, sempre destinando atenção sobretudo a componentes de naturezas etiológica, epidemiológica, diagnóstica, terapêutica e preventiva. Prevê outrossim a execução de investigações científicas correlatas, de preferência aplicadas, e ajudas a comunidades.

Progressivamente, em seguida aos exemplos advindos de poucos baluartes, houve crescimento da quantidade de novos adeptos e variados acontecimentos permitiram consolidar a crescente arregimentação de infectologistas nacionais. Entre essas iniciativas valorosas cito, como ilustrações, iniciativas implementadas: cursos de pós-graduação; Sociedades Cientíicas; Congressos, simpósios e promoções congêneres para atualizações, além do relato de produtivas pesquisas; concursos em setores públicos; título de especialista atribuído pela Associação Médica Brasileira; Disciplina ou Departamento em instituições universitárias; boletins erevistas atinentes só à especialidade; livros pertinentes. Então, hoje há decisivamente a Infectologia brasileira, que inclusive chegou à Pediatria.
Verificou-se 0 arrefecimento de doenças em virtude de motivos variados e, mormente, como decorrência de vacinações. Contudo despontaram outras, como a doença de Lyme, a febre purpúrica brasileira, a angiomatose bacilar, ao lado da percepção de que as infecções pelos vírus $\mathrm{B}$ eC da hepatite têm dimensões bem superiores às tidas como bastante prevalentes. Vieram ocorrências epidêmicas: doença meningocócica, cólera, dengue, aids eleptospirose, referidas só para não deixar de destacá-las. Devo aduzir a obrigatoriedade de manter atenção no que tange às doenças emergentes, ampliando a dimensão do que cabe a infectologistas.

Năo bastasse tudo isso, processou-se agregação de mais tarefas: a coordenação e supervisão do uso de antimicrobianos ou de imunobiológicos; prestação de cuidados de naturezas diagnóstica e terapêutica a imunodeprimidos, a enfermos com complicações infecciosas pós-cirúrgicas ou a quem recebeu órgãos por transplantes; dedicação a assuntos referentes às infecções hospitalares.

Portanto, a abrangência da Infectologia no Brasil cresceu sensivelmente por causa de missões acrescidas de forma paulatina, sensata ejudiciosa. Configurado esse panorama, preocupado notei que há quem proponha, talvez para conseguir simplória notoriedade, fatiamento da especialidade em Infectologia velha e Infectologia nova. Éidealização extravagante, chegando a parecer que atenção relativa às moléstias qualificadas como tropicais afigura-se desprimorosa, antiquada e medieval. Novas tarefas não são substrato para inventar separação criteriosamente indefensável.

As leishmanioses mucocutânea e visceral estão tendo marcante disseminação. A esquistossomíase mansônica ficou melhor combatida através de tratamentos simples e eficazes, mas continua por aí. Para a doença de Chagas é imperiosa dedicação para coibir a transmissão do Trypanosoma cruzi por mecanismos alternativos. Mesmo que se afigurem relevantes esses exemplos parciais, peço para que não seja esquecida a malária, de difícil controle e a mais proeminente doença infecciosa no Brasil.

Como especulação anoto que para que múltiplas enfermidades etiologia infecciosa encontra-se provada ou suspeitada: temor de Burkitt, sarcoma de Kaposi, câncer do colo do útero, paraparesia

1. Laboratório de Investigação Médica Parasitologia do Departamento de Moléstias Infecciosas e Parasitárias do Hospital das Clínicas da Faculdade de Medicina da Universidade de São Paulo, São Paulo, SP.

Endereço para correspondência: Prof. Vicente Amato Neto. Laboratório de Investigação Médica-Parasitologia/DMI/HC/FM/USP. Av. Dr. Enéas de Carvalho Aguiar 470, 05403-000 São Paulo, SP.

Tel: 11 3066-7042, Fax: 11 3081-8144

e-mail:amatonet@usp.br

Rebido para publicação em 8/4/2004

Aceito em 21/5/2004 
tropical, leucemia, obesidade, diabetes do tipo 1 e esclerose múltipla. Então, logo mais surgirá a intenção de criar a Infectologia novíssima.

Infectologistas: o país precisa de vocês, atualizados e aguerridos, labutando nos setores vocacionalmente preferidos, representando mero circunlóquio o nada construtivo fatiamento comentado.

Convém não esquecer as histórias de cientistas tropicalistas, que tiveram honrosas repercussões em nível internacional.
Foram inclusive paradigmas para a evolução científica nacional. A respeitadíssima Fundação de Amparo à Pesquisa do Estado de São Paulo divulgou recentemente comentário segundo 0 qual 0 Brasil mantém pioneirismo na investigação e na prevenção de doenças típicas de paises pobres. Esses estilo e exemplo obrigatoriamente persistirão, a fim de aprimorar conhecimentos ainda insuficientes sobre aspectos imunológicos, patogenias e tratamentos, ainda insatisfatórios no que concerne a males ainda vigentes na presente epidemiologia tropical.

\section{Vicente Amato Neto ${ }^{1}$}

